\title{
The Pathogenesis of Urinary Tract Infections
}

\author{
Niall F. Davis and Hugh D. Flood \\ Department of Urology, Mid-Western Regional Hospital, \\ Dooradoyle, Co. Limerick, \\ Ireland
}

\section{Introduction}

Urinary tract infections (UTIs) are among the most common conditions requiring medical treatment with $6-10 \%$ of all young females demonstrating bacteriuria (Raz 2001). The incidence of UTIs increases with age and $25-50 \%$ of females aged 80 or more have bacteriuria (Abrutyn et al. 1988). UTIs occur as a result of interactions between the uropathogen and host and their pathogenesis involves several processes. Initially the uropathogen attaches to the epithelial surface; it subsequently colonises and disseminates throughout the mucosa causing tissue damage. After the initial colonisation period, pathogens can ascend into the urinary bladder resulting in symptomatic or asymptomatic bacteriuria. Further progression may lead to pyelonephritis and renal impairment. Specific virulence factors residing on the uropathogen's membrane are responsible for bacterial resistance to the normally effective defence mechanisms of the host. Recently, bacterial adhesins and their associated epithelial binding sites have been identified and natural antiadherence mechanisms are currently under investigation.

An understanding of pathogenic and anti-adherence mechanisms may allow physicians to develop appropriate strategies for UTI prevention and adequate management protocols. In the present chapter we discuss current concepts on the pathogenesis of UTIs with particular emphasis on pathogenic bacteria, virulence factors, predisposing factors, natural defences within genitourinary tract and consequences when these defence mechanisms are altered.

\section{Routes of infection}

In healthy patients most uropathogens originate from rectal flora and enter the urinary tract via the urethra into the bladder (Handley et al. 2002). This is known as the ascending route and uropathogens initially adhere to and colonise urothelium of the distal urethra (Fig.1). Enhancement of this route is exacerbated in patients with soiling around the perineum, in patients with urinary catheters and in females that use spermicidal agents (Foxman 2002). In patients with established cystitis up to $50 \%$ of infections may ascend into the upper urinary tracts and most episodes of pyelonephritis are caused by ascension of bacteria from the bladder through the ureter and into the renal pelvis (Busch and Huland 1984). Bacterial ascent is aided by conditions such as pregnancy and ureteral obstruction as these conditions inhibit ureteral peristalsis. Bacteria that reach the renal pelvis can penetrate the renal parenchyma through the collecting ducts and disrupt the renal tubules. 
In healthy individuals infection of the kidney through the haematogenous route is uncommon. Occasionally, the renal parenchyma may be breeched in patients with Staphylococcus aureus bacteraemia or Candida fungaemia that originate from oral sources in immunosuppressed patients (Smellie et al. 1975). On rare occasions bacteria from adjacent organs may penetrate the urinary tract via the lymphatics. Conditions associated with the lymphatic route are retroperitoneal abscesses and severe bowel infections.

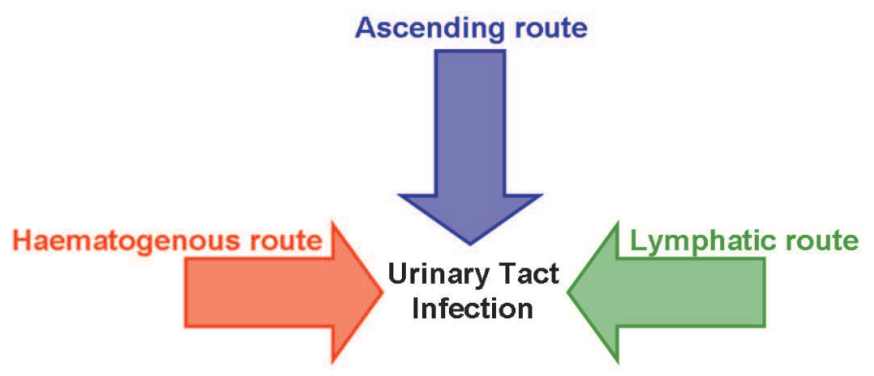

Fig. 1. Urinary tract infections may arise from ascending, haematogenous or lymphatic routes. Ascending routes of infection are most common among patients with an established UTI.

\section{Urinary pathogens}

\subsection{Pathogenic bacteria}

E. coli accounts for $85 \%$ of community acquired and $50 \%$ of hospital acquired urinary tract infections. Within the E.coli species a number of subgroups $(\mathrm{O} 1, \mathrm{O} 2, \mathrm{O} 4, \mathrm{O} 6, \mathrm{O}$, O8, O18, O25, O68 and O75) are frequently isolated from patients with UTI (Brooks et al. 1981, Gruneberg 1969, Roberts and Phillips 1979, Vosti et al. 1964). Gram negative bacteria such as Klebsiella and Proteus; and Gram positive Enterococcus faecalis and Staphylococcus saprophiticus are causative agents for the remainder of community acquired infections (Kennedy et al. 1965). The remainder of hospital acquired infections usually occur after colonisation with Klebsiella, Enterobacter, Citrobacter, Serratia, Pseudomonas aeruginosa, Providencia, E. faecalis, or S. epidermidis (Kennedy et al. 1965). Notably, the patient's age may influence they type of infective organism present with Staphylococcus saprophiticus now accounting for $10 \%$ of UTIs in young females compared to less than $1 \%$ in elderly female patients.

\subsection{Uncomplicated UTIs}

UTIs can be classified as either complicated or uncomplicated depending on underlying host factors and on underlying uropathogens as illustrated in table 1. The aetiology of uncomplicated UTIs has remained constant over the last 2 to 3 decades with E. coli accounting for the vast majority of cases. Previously, female patients with uncomplicated UTIs generally remained sensitive to a trimethoprim-sulfamethoxazole combination and the traditional approach to therapy had been an empirical short-course treatment with this antibiotic regimen (Hooton and Stamm 1997, Stamm and Hooton 1993). Unfortunately, a number of more recent studies have demonstrated increasing antimicrobial resistance among uropathogens causing uncomplicated cystitis and traditional antibiotic regimens 
have been questioned (Gupta et al. 1999). One study investigated antimicrobial resistance among 4000 female petients with UTI isolates over a 5 year experimental time period. Results from this study demonstrated an increase in antimicrobial (E. coli) resistance from $9 \%$ to $18 \%$ in patients treated with trimethoprim-sulfamethoxazole (Gupta et al. 1999). In addition, resistance to cephalothin (a first generation cephalosporin) increased from $20 \%$ to $28 \%$ and resistance to ampicillin increased from $26 \%$ to $34 \%$. Notably, resistance to nitrofrantoin and ciprofloxacin remained $<1 \%$ after the 5 year period. This increase in bacterial resistance has been attributed to recent administration of trimethoprimsulfamethoxazole, diabetes mellitus, recent hospitalisation and recent administration of any other antibiotic (Wright et al. 1999).

Clinical implications for increasing resistance trends include a potential alteration to antibiotic regimens commonly administered for treating uncomplicated UTIs. One study demonstrated a greater cure rate after a 7-day course of ciprofloxacin compared to a 14-day course of trimethprim-sulfamethoxazole in premenopausal females with uncomplicated pyelonephritis (Talan et al. 2000). In this study it is also notable that E. coli resistance to trimethoprim-sulfamethoxazole was significantly greater $(18 \%)$ compared to ciprofloxacin $(0 \%)$. Lower cure rates for uncomplicated UTIs in females treated with trimethoprimsulfamethoxazole have also been demonstrated in another study where failure rates increased from 3\% to $13 \%$ in sensitive E.coli strains and from $27 \%$ to $40 \%$ in resistant strains (McCarty et al. 1999). Based on these studies antimicrobial treatment with either a fluoroquinolone, nitrofurantoin or fosfomycin are currently recommended for uncomplicated UTIs. Importantly, clincians should also be aware of the antimicrobial spectrum for these agents prior to administration as nitrofurantoin is not effective for treating uncomplicated pyelonephritis but highly effective for treating acute cystitis. Recurrent uncomplicated UTIs occur after 3 to 6 months in $25 \%$ to $35 \%$ of patients after their initial UTI. The second strain is caused by an identical strain to the first UTI in up to $60 \%$ of patients with recurrent UTI (Ronald 2003).

\subsection{Complicated UTIs}

Underlying host factors such as age, catheterisation, diabetes mellitus and spinal cord injury predispose to complicated UTIs (Fig. 2). In complicated UTIs less virulent uropathogens (that rarely cause disease in a normal urinary tract) can cause significant damage to an abnormal urinary tract. Studies have demonstrated associations between Group B streptococcal bacteraemia, Candida and Enterococci with complicated UTIs in the elderly population (Khan and Ahmed 2001, Munoz et al. 1997).

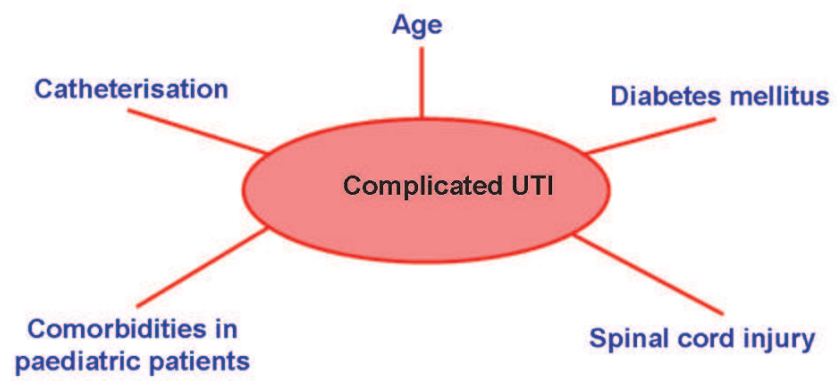

Fig. 2. Predisposing factors for complicated UTIs. 
Children with comorbidities are more likely to develop complicated UTIs and Staphylococcus aureus is the most frequently isolated micro-organism in paediatric patients with indwelling catheters (Schlager 2001). Candida and coagulase-negative staphylococci are associated with complicated UTIs after instrumentation of the paediatric urinary tract. Of note, enterobacteriaceae are the most frequently isolated uropathogen in children with uncomplicated UTIs (Schlager 2001).

UTIs are among the top 10 complicating illnesses in patients with diabetes mellitus with E. coli, Klebsiella, Group B Streptococci and Enterococcus among the common uropathogens (Ronald and Ludwig 2001). In fact, Group B Streptococcus and Klebsiella are 2-3 times more common in patients with diabetes mellitus than in patients without the condition (Ronald and Ludwig 2001). However, E. coli remains the most causative uropathogen for UTIs in patients with diabetes as demonstrated in one prospective study where E. coli was isolated in $56.1 \%$ of diabetic patients with a UTI (Bonadio et al. 1999). There is a higher rate of bladder catheterisation in patients with diabetes and this factor may partially account for the higher incidence in this patient cohort (Ronald 2003).

Common uropathogens causing complicated UTIs among patients with spinal cord injuries and indwelling catheters include E. coli, Pseudomonas and Proteus mirabilis (Mobley et al. 1994). The latter is particularly associated with complicated UTIs as it possesses unique virulence factors that enhance its invasive potential (Coker et al. 2000). One study demonstrated a significant increase in nosocomial UTIs from 2.63 of 1000 patient days to 4.35 of 1000 patient days over a 9 year period ( $\mathrm{p}<0.003$ ). Notably, $88 \%$ of nosocomial UTIs in this study were catheter related (Bronsema et al. 1993).

\begin{tabular}{|c|c|}
\hline Pathogens in uncomplicated UTIs & Pathogens in complicated UTIs \\
\hline Escherichia coli & Escherichia coli \\
Staphylococcus saprophyticus & Kelbsiella \\
Kelbsiella & Enetrobacter cloacae \\
Enterococcus faecalis & Serratia marcescens \\
& Proteus mirabilis \\
& Pseudomonas aeruginosa \\
& Enterococcus faecalis \\
& Group B streptococci \\
\hline
\end{tabular}

Table 1. Underlying uropathogens commonly isoloated in complicated and uncomplicated urinary tract infection (UTI) (Ronald 2003).

\section{Bacterial adherence mechanisms}

\subsection{Virulence factors}

Bacterial virulence factors play a significant role in determining whether an organism will invade the urinary tract and the level of infection acquired. Uropathogenic E. coli (UPEC) is present within bowel flora and pathogenic strains of this microorganism can infect the urinary tract by expressing specific virulence factors that permit adherence and colonisation of the lower urinary tract (Schlager et al. 2002, Yamamoto et al. 1997). Adherence of the micro-organism is dependent on 3 important environmental characteristics; firstly the bacteria's own adhesive characteristics, secondly the receptive features of the urothelium and finally the fluid that is present between both surfaces (Schaeffer et al. 1981). Bacteria 
will migrate proximally and precipitate a host derived inflammatory response after adhering to the mucosal surface.

Adhesins found on the surface of the bacterial membrane are responsible for initial attachment onto urinary tract tissues (Mulvey 2002) (Fig. 3).

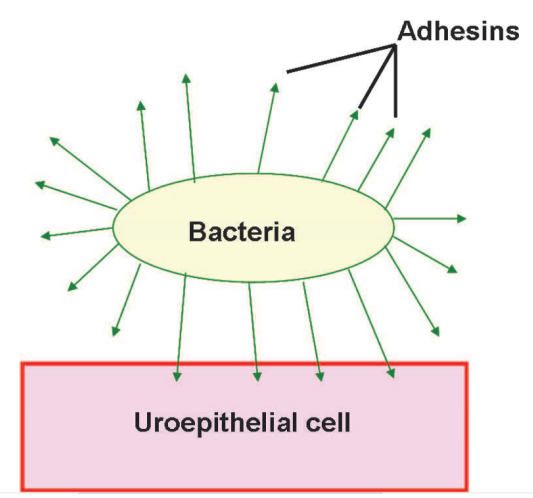

Fig. 3. Adhesins on the uropathogen are responsible for attachment of the bacteria to the uroepithelial cell membrane of the host.

Adhesins are classified as fimbrial or afimbrial, depending on whether the adhesin is displayed as part of a rigid fimbria or pilus. Fimbriae and pili are surface glycoproteins that function as ligands for glycolipid and glycoprotein receptors on uroepithelial cells. Bacteria may produce 100-400 pili on the same cell and other cells can produce the same pilus type. Each pilus is $5-10 \mu \mathrm{m}$ in diameter and up to $2 \mu \mathrm{m}$ in length (Klemm 1985). A pilus is composed of subunits referred to as pilin and they are classified as either mannose sensitive or mannose resistant, based on their ability to mediate haemagglutination of erythrocytes. The most common types of pili are types 1, P and S. Assemblance of pili within the urinary tract is mediated by the 'chaperone/ usher pathway' where periplasmic chaperones such as $\mathrm{P}$ pilus chaperone 'PapD' and type 1 pilus chaperone 'FimC' possess two immunoglobulin (Ig)-like domains that are oriented to form a boomerang like shape (Kau et al. 2005, Kuehn et al. 1993, Lau et al. 2005). These chaperones are important for binding with pilus subunits to form stable complexes. The FimC chaperone accelerates the folding of type 1 pilus subunits to strengthen its binding process after its initial attachment process (Vetsch et al. 2004).

\subsection{Type 1 pili}

Type 1 pili are also referred to as mannose sensitive pili and they are commonly expressed in pathogenic and non pathogenic strains of E. coli. They are termed mannose sensitive as haemagglutination of erythrocytes is inhibited in the presence of mannose (Reid and Sobel 1987). Type 1 pili are composed of a helical rod with repeating Fim A subunits that are bound to a distal tip structure containing the Fim H adhesin (Jones et al. 1995). During the colonisation process Fim $\mathrm{H}$ adhesins bind to mannosylated receptors that are found on the host's uroepithelium. An inflammatory process occurs shortly after this binding process has been initiated. A number of studies have demonstrated that interactions between the Fim $\mathrm{H}$ adhesin and epithelial cells on the bladder's surface are essential for colonisation and 
infection of bladder epithelium with strains of uropathogenic E. coli (Sun 1996, Wu et al. 1996). This specific 'adhesin-epithelial cell' binding process occurs when type 1 pili bind to uroplakin 1a (UP1a) and uroplakin 1b (UP1b) (Malaviya and Abraham 1998). (Fig. 4) Uroplakins are membrane proteins that are found on umbrella cells which line the luminal surface of the urinary bladder. Initially adhesin binding mechanisms were investigated in a mouse cystitis model where numerous bacteria attached to the urothelial surface of the mouse urinary tract shortly after an inoculation period. Scanning electron microscopy of the urothelial layers demonstrated that Fim $\mathrm{H}$ containing pili bound to the central cavity of uroplakin hexameric rings and this binding process is responsible for the initial steps leading to active UTI (Mulvey et al. 1998).

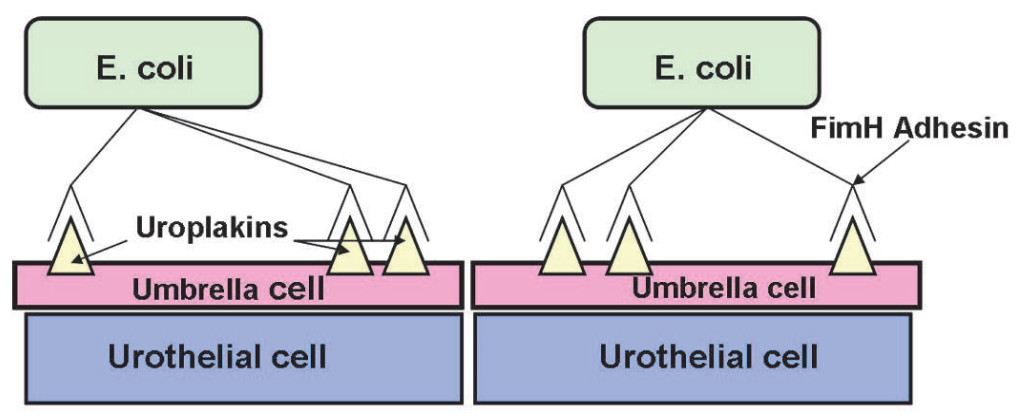

Fig. 4. During the colonisation period FimH adhesins bind to umbrella cells via uroplakin 1a and uroplakin $1 \mathrm{~b}$ membrane receptors.

After binding to the epithelial surface the activated Fim $\mathrm{H}$ adhesins migrate towards deeper urothelial layers and penetrate the cell membrane (Mulvey et al. 2000). Once the uropathogen is intracellular the invasive process continues as bacteria proliferate within the cytosol to form clusters (Anderson et al. 2004b). Eight hours after inoculation the phenotypic appearance of the bacteria changes to an engulfing 'biofilm' like structure that protects against the host's immune response and shields the uropathogen from its surrounding environment (Justice et al. 2004) (Fig. 5). A decrease in the rate of bacterial proliferation will allow for effective production of a 'biofilm matrix'. This matrix can prevent the host's neutrophils from penetrating its surface. The 'biofilm' concept stems from the idea that bacteria co-operate with one another to remain viable and proliferate after attaching to a suitable substrate. Previously, it has been demonstrated that biofilms play an important role in a number of disease processes (Kau et al. 2005, Parsek and Singh 2003). Bacterial biofilms can form within infected urinary tract calculi, during Pseudomonas infections in patients with cystic fibrosis and in infective endocarditis. During the disease process biofilms form irreversible associations with their host by forming extracellular polysaccharides that have specialised functions (Justice et al. 2004).

Biofilms can form on many different types of bacteria however the sequence of events during the 'formation process' remains similar in all bacteria. Firstly, bacteria express extracellular polymeric substances that are initially reversible and subsequently become irreversible. Bacteria that have irreversibly attached to a surface will serve as a nidus for continued replication and recruitment of other bacteria. Irreversible attachment is usually established after 24 hours where the bacteria will develop into a complicated 'tower' like 
structure and become filamentous (up to $70 \mu \mathrm{m}$ in length). Morphological changes allow the uropathogen to evade the host's immune response (Justice et al. 2004). Bacteria that have clustered will eventually detach from their group, become motile and flee the host cell. Bacterial adherence and replication will recur after the uropathogen escapes its intracellular environment and this effective replication process will allow bacterial invasion to persist (Anderson et al. 2004a) (Fig. 5).

A.

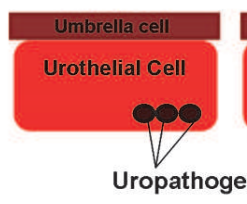

c.

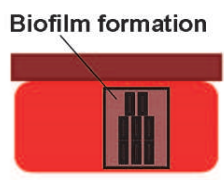

B.

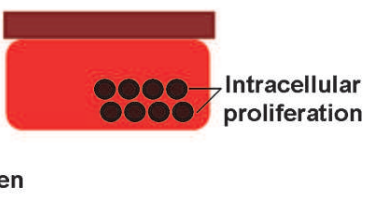

D.

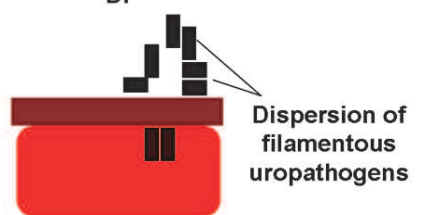

Fig. 5. After attaching to the epithelial surface the uropathogen will enter the cytosol (A). Intracellular bacteria rapidly proliferate within the first 24 hours (B). Subsequently, proliferation rate decreases and a protective biofilm matrix forms (C). Morphological changes allow the uropathogen to evade the host's immune response. Uropathogens that have clustered become motile and detach from the biofilm to disperse (D).

\subsection{P Fimbriated pili}

$P$ fimbriated pili or mannose resistant strains of E. coli are associated with uncomplicated pyelonephritis as the receptor for $\mathrm{P}$ fimbriae is the major glycolipid component present on renal cell membranes (Mulvey 2002). They are termed mannose resistant as they are not affected by mannose during the haemagglutination process for human erythrocytes (Vaisanen et al. 1981). PapG is an adhesin found at the tip of the pilus and it recognizes the a-d-galctopyranosyl-(1-4)- $\beta$-d-galctopyranoside receptor which is found on P-blood group antigens on the host's uroepithelium (Kallenius et al. 1981) (Fig. 6). Mannose resistant adhesins that do not demonstrate digalactoside-binding affinity are referred to as ' $X$ ' adhesins. A correlation between severe UTIs and bacterial adherence was first identified in 1976 (Eden et al. 1976). Strains of uropathogenic E. coli in girls with established pyelonephritis had an adhesive ability of $70-80 \%$ compared to $10 \%$ in strains that caused asymptomatic bacteriuria. $\mathrm{P}$ pili were present in $91 \%$ of strains that caused pyelonephritis compared to a prevalence of $7 \%$ in bowel isolates from healthy children (Eden et al. 1976). Although mannose resistant haemagglutinins (MRHA) are associated with pyelonephritis it is important to note that no link exists between MRHA and renal scarring.

\subsection{Phase variation}

Interestingly, in vivo studies have shown that environmental factors are responsible for rapid changes in pili in E. coli isolates. This transformation process is known as known as 


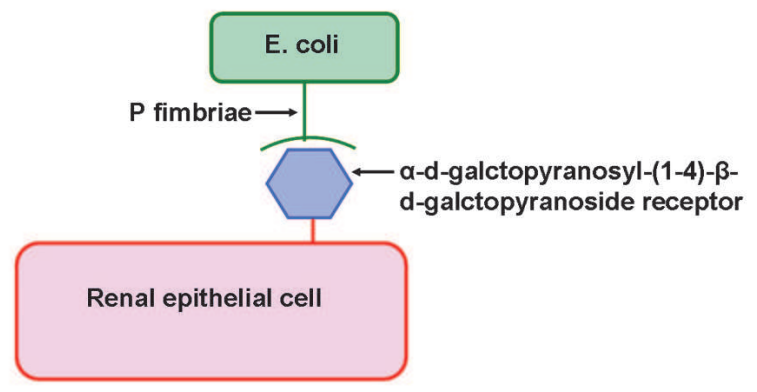

Fig. 6. P fimbiae bind to the a-d-galctopyranosyl-(1-4)- $\beta$-d-galctopyranoside receptor on the host's renal epithelial cell via the PapG adhesin.

phase variation and it involves alternating periods of piliated and nonpiliated adhesins during in vivo E. coli infection (Hultgren et al. 1986, Schaeffer et al. 1987). One study showed phase variation of pili using indirect immunofluorescense assays of voided urine in human patients. Analysis of the urine samples showed type 1 pili in 31 of 41 samples and P pili in 6 of 18 samples with piliation status varying from predominantly piliated to nonpiliated cells (Kisielius et al. 1989). These results demonstrated that type 1 and $\mathrm{P}$ pili are expressed and subject to phase variation in vivo during acute UTIs. The process of phase variation among adhesins has notable clinical implications. Importantly, the presence of type 1 pili may facilitate adherence and colonisation of the host's mucosa in the lower urinary tract. However, P pili may predominate as the infective process progresses and ascends. This transformation process occurs because primary mediators for the attachment of $\mathrm{P}$ pili to their glycolipid receptors are found within the kidney (Mulvey et al. 1998).

\subsection{Cell receptivity}

Epithelial cell receptivity also plays an important pathogenic role in female patients that are susceptible to recurrent UTI. The receptivity concept was established after vaginal epithelial cells were collected from patients susceptible to recurrent UTI with E. coli and compared with control samples that were resistant to UTI (Fowler and Stamey 1977). Results from this study demonstrated that strains of E. coli associated with cystitis ardently adhered to vaginal epithelial cells of susceptible females. Notably, buccal cell receptivity is also increased for different strains of E. coli in females with increased vaginal cell receptivity. These findings indicate a genotypic trait as the increase in receptor sites for strains of E. coli is not confined to the vagina in females with recurrent UTIs. Further analysis of this genetic concept by assessing human leukocyte antigens (HLAs) in females with recurrent UTIs has demonstrated that HLA-A3 may be a contributing factor. It has also been shown that a greater number of uropathogens attach to epithelial cell surface in females that are greater than 65 years of age compared to premenopausal females (i.e. age 18-40) (Schaeffer et al. 1983).

\section{Predisposing factors for pathogenic adherence}

\subsection{Alterations to the host's natural defence mechanisms}

Normal flora around the vaginal introitus, periurethral region and urethra include microorganisms such as lactobacilli, coagulase negative staphylococci and streptococci that 
form a barrier against pathogenic colonisation. Alterations in the vaginal mucosa and decreases in its $\mathrm{pH}$ are thought to play an important role for with coliforms (Hooton et al. 1996a). Acute disruptions to this mucosal barrier are frequently attributed to spermicidal and antimicrobial agents that alter normal flora and induce increased receptivity for uropathogens (Hooton et al. 1996a). Host factors that contribute to the disruption of this mucosal barrier are illustrated in table 2 .

Comorbidities such as diabetes mellitus, sickle cell disease, hyperphosphataemia, gout and analgesics are also associated with altering the host's natural defence mechanisms (Freedman 1975). The incidence of pyelonephritis is up to fivefold higher in diabetics compared to non diabetic patients (Nicolle et al. 1996). Furthermore, female patients with diabetes mellitus are 3 times more likely to develop pyelonephritis compared to male patients with the condition (Nicolle et al. 1996). Diabetes also predisposes patients to more complicated UTIs with an inflammatory urothelial response occurring in the upper tracts of up to $80 \%$ of diabetic patients with UTIs (Forland et al. 1977, Stapleton 2002). In addition, UTIs in this patient cohort are often caused by atypical organisms and complications may progress to include papillary necrosis, perinephric abscesses or multisystemic infections (Stapleton 2002).

Urinary tract obstruction and stasis of urine flow can significantly alter the host's defence mechanisms and both factors strongly predispose to complicated UTIs (Hooton 2000). During the obstructive process local mucosal defence mechanisms are disturbed as the epithelial lining over-distends and pooled urine functions as a mean for bacterial growth and proliferation (Hooton et al. 2000). Urinary catheters, particularly in patients with high residual volumes, are also ideal media for uropathogens to colonise the urinary tract. Finally, fistulae can facilitate direct access into the genoitourinary tract via the gastrointestinal system.

\begin{tabular}{|c|c|c|c|}
\hline Genetic & Biological & Behavioural & Others \\
\hline $\begin{array}{l}\text { Blood group antigen } \\
\text { Non-secretor status } \\
\text { Increased density of } \\
\text { adhesion receptors }\end{array}$ & $\begin{array}{c}\text { Congenital } \\
\text { abnormalities } \\
\text { Urinary obstruction } \\
\text { Calculi } \\
\text { Diabetes mellitus } \\
\text { Anatomical } \\
\text { Residual urine } \\
\text { Atrophic vaginitis } \\
\text { Urinary incontinence } \\
\text { Prior history of UTI } \\
\text { Maternal history of } \\
\text { UTI } \\
\text { Urinary catheters } \\
\text { Stents } \\
\text { Immunological } \\
\text { deficiency (HIV) } \\
\text { Renal transplant }\end{array}$ & $\begin{array}{l}\text { Sexual intercourse } \\
\text { Use of diaphragm } \\
\text { Use of spermicides } \\
\text { Antimicrobial use }\end{array}$ & $\begin{array}{c}\text { Decreased } \\
\text { mental status }\end{array}$ \\
\hline
\end{tabular}

Table 2. Host factors that contribute to the pathogenesis of UTIs in female patients. 


\subsection{Anatomical and physiological factors}

It is widely acknowledged that a number of factors contribute to a greater prevalence in UTIs in females compared to males. In particular, female pelvic anatomy plays an important predisposing role for recurrent UTIs in female patients. One study investigated differences in perineal anatomical measurements and voiding characteristics in 100 females with a history of recurrent UTIs and in 113 females with no prior history of UTIs. Analysis of the results demonstrated that the urethra and anus were significantly closer together in cases of UTI $(4.8 \pm 0.6 \mathrm{~cm})$ compared to controls $(5.0 \pm 0.7 \mathrm{~cm}, \mathrm{p}=0.03)$ (Hooton 2000). Other important physiological and anatomical factors that predispose to bacterial adherence in females (compared to males) include a drier urethral meatus, a shorter urethra and the absence of antibacterial properties provided by prostatic fluid (Lipsky 1989).

\subsection{Spermicidal compounds}

Nonoxynol-9 is a non-ionic surfactant that is the most active ingredient found in spermicidal compounds in the USA. Results from in vitro studies have shown that it is less active against uropathogenic bacteria compared to Lactobacillus (Hooton et al. 1991a, McGroarty et al. 1990) with hydrogen peroxide-producing strains being particularly susceptible (Hooton et al. 1991a). Therefore, it appears that vaginal colonisation with hydrogen peroxide vaginal strains of lactobacilli may play an important role in bacterial resistance (Eschenbach et al. 1989). This hypothesis has been tested in other studies where hydrogen peroxide-producing lactobacilli had a protective effect against bacterial vaginosis, symptomatic candidosis and vaginal colonisation with genital pathogens (Hawes et al. 1996, Hillier et al. 1992). In support of this hypothesis one case-control study has also demonstrated that vaginal colonisation with E. coli occurs more frequently in females without hydrogen peroxideproducing lactobacilli compared to females with these strains (odds ratio 4.0; $\mathrm{p}=0.01$ ) (Gupta et al. 1998). In this study, spermicidal use among females correlated with an increased risk of vaginal colonisation with E. coli (odds ratio 12.5; $\mathrm{p}<0.001$ ) and with the absence of hydrogen peroxide-producing lactobacilli. Another study also showed decreased vaginal lactobacilli and an increase in vaginal coliforms after nonoxynol-9 instillation in the absence of sexual activity and diaphragm use (Rosenstein et al. 1998).

Based on these studies, it seems likely that the antimicrobial activity of spermicides alters the vaginal ecosystem and provides a suitable environment for growth and proliferation of uropathogens. It is interesting to note that small amounts of nonoxynol-9 on condoms can increase the risk of UTI in females in the absence of sexual intercourse (Fihn et al. 1998, Fihn et al. 1996).

\subsection{Premenopausal females}

In premenopausal healthy females sexual intercourse and spermicide use are the most important factors predisposing to UTIs. One study demonstrated a 2.6 fold increased risk of UTI in females (age 24) that have sexual intercourse 3 times a week compared to females that do not have intercourse (Hooton et al. 1996a). It is hypothesised that an increased risk of UTI from sexual intercourse occurs from trauma at the introitus (Foxman et al. 1997, Hooton et al. 1991b) or through mechanical introduction of the uropathogen into the bladder (Hooton et al. 1991b). Other predisposing factors to UTI in premenopausal patients are a new sexual partner during the last year, having a first UTI less than 15 years of age and having a mother with a history of UTIs (Hooton et al. 1996a). Interestingly, the latter two are 
associated with a two- to four- fold increase in risk compared to normal females, perhaps suggesting a genetic predisposition. Finally, a previous history of UTI is a strong predictor of having a subsequent UTI. This may be attributable to a host's biological or behavioural features or from persistent colonisation of a particular bacterial strain.

\subsection{Oestrogen}

The role of oestrogen in the pathogenesis of UTIs is controversial. In vitro studies have demonstrated that oestrogen permits adherence of uropthogens to vaginal epithelial cells (Hooton et al. 1996b). However, other studies also suggest that oestrogen deficiency in postmenopausal females may increase the risk of UTI (Haspels et al. 1981, Thomas et al. 1980). In fact, one study showed that half of females aged 61 or older had genitourinary symptoms and $29 \%$ of this cohort also complained of urinary incontinence (Iosif and Bekassy 1984). Furthermore, the risk of UTI in postmenopausal females is decreased by topical application of oestrogen creams as demonstrated in one double-blinded-placebo controlled study (Raz and Stamm 1993). In this study results showed that vaginal colonization with E. coli was halved and lactobacillus colonization was re-established after topical application of oestrogen in postmenopausal females (Fig. 7). As a result vaginal $\mathrm{pH}$ was decreased along with colonisation with Enterobacteriaceae.

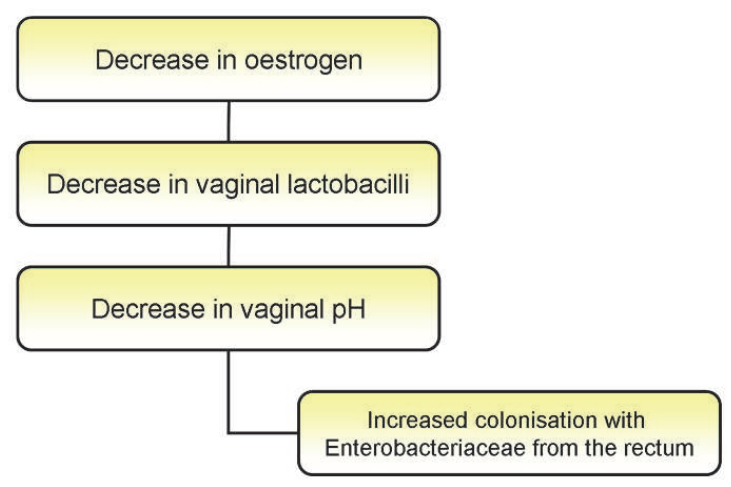

Fig. 7. Proposed pathophysiology of UTIs in patients with oestrogen deficiency (Raz 2001).

\subsection{Genetic susceptibility}

Interleukin-8 is an inflammatory cytokine that promotes neutrophil migration across infected urothelial cells (Godaly et al. 1998, Godaly et al. 1997). Absence of its receptor CXCR1 has recently been shown to promote bacteraemia within the urinary tract as demonstrated in one study in knockout mice that lacked CXCR1 (Frendeus et al. 2001). A genetic predisposition to UTIs has been suggested in paediatric patients where children with recurrent pyelonephritis demonstrated a defect in the CXCR1 receptor (Frendeus et al. 2000).

\subsection{Antimicrobial agents}

Animal and human studies suggest that antimicrobial agents predispose females to UTIs by altering their host's vaginal ecology (Herthelius-Elman et al. 1992, Winberg et al. 1993). 
Colonisation with E. coli is increased after administering $\beta$-lactam antimicrobial agents in monkeys (Herthelius-Elman et al. 1992). Notably, trimethoprim and nirofuarantoin do not enhance vaginal colonisation with E.coli in similar trials on monkeys and these findings suggest that $\beta$-lactam antibiotics may be responsible for altering the genital flora of female patients. Less vaginal colonisation with uropathogens occurs after a course of cotrimoxazole or fluoroquinolones when compared to $\beta$-lactam antimicrobials. Finally, the timing of antimicrobial agents also appears to play a role for increasing the risk of UTI. One prospective study on premenopausal females demonstrated an increased risk for UTI in females that had been prescribed antimicrobial therapy during the preceding 15-28 days compared to the previous 3-14 days (Smith et al. 1997).

\subsection{Urological factors}

Several urological factors are associated with a predisposition to UTIs in female patients. Cystocele, high post-void residual volume and urinary incontinence are strongly associated with recurrent UTIs as demonstrated in one case control study (Raz et al. 2000). In addition, surgery of the genitourinary tract often precedes the onset of a UTI and urological surgery itself is also an independent risk factor for recurrent UTI (Raz et al. 2000).

\section{Host response to pathogenic adherence}

A series of defence pathways are activated by the host after the uropathogen adheres to the mucosal surface. Epithelial cells exfoliate within hours of the initial infection and infected urothelial cells are shed during this process (Mysorekar et al. 2002). Secretion and excretion of the infected urothelial cells is mediated by type 1 piliated bacteriae that induce cell apoptosis (Mulvey et al. 1998). In healthy patients the epithelium lining the surface of the bladder is quiescent as the umbrella cell layer is renewed every few months. However these normally repressed proliferation and differentiation cascades are rapidly activated after the infective process in the murine cystitis model. These proliferation cascades have the potential to induce effective regeneration of an umbrella cell layer within 24 hours of the exfoliation process (Fig. 8) Another study in mice has demonstrated that exfoliation of urothelial cells prevents uropathogenic E. coli from forming clusters (Anderson et al. 2004b). Notably, mice that elicited a mild exfoliation process in response to the uropathogen were more likely to form biofilms that migrated into deeper layers.

The host's innate immune response is primarily responsible for providing resistance to the invading uropathogen. Numerous cell types such as neutrophils, macrophages, eosinophils and natural killer cells are activated as the uropathogen invades. In addition, polymorphonuclear leukocytes synthesise nitric oxide by increasing the transcription of nitric oxide synthase and this process has a toxic effect on the invading pathogen (Poljakovic and Persson 2003, Poljakovic et al. 2001). During the initial inflammatory response period it is important to note that neutrophils play a key role as they migrate towards the infected site. The migratory process is mediated by pathogen-associated molecular pattern receptors (PAMPs) and Toll-like receptors (TLRs) (Anderson et al. 2004b). After lipopolysaccharides (LPS), peptidoglycans (PG) and other bacterial products are recognised TLRs activate signalling pathways that initiate immune and inflammatory responses to kill pathogens (Anderson et al. 2004a). TLR4 and its co-receptors (CD14 and MD2) recognise Gramnegative bacterial LPS and activate the innate immune response (Haraoka et al. 1999). In addition, TLR11 is released from the kidney and activated to prevent the infection from 
ascending towards the renal parenchyma (Zhang et al. 2004). Notably, more recent studies have demonstrated that uropathogens can suppress NFKB and consequentially decrease the host's inflammatory response. This tactic allows the uropathogen to invade into deeper tissues (Klumpp et al. 2001). After 7-10 days the adaptive immune response is activated where specific uropathogens are recognised by $\mathrm{B}$ and $\mathrm{T}$ lymphocytes with high affinity antibodies.

A.

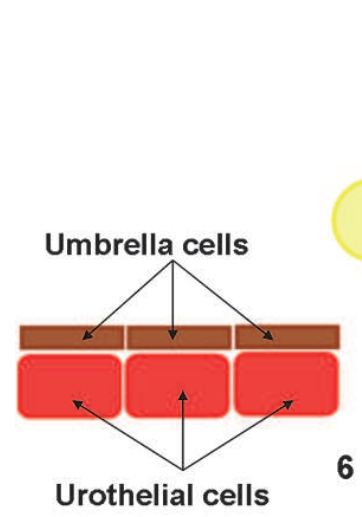

B.

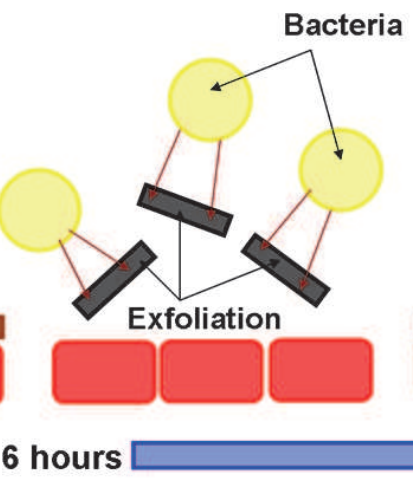

c.

\section{Regeneration}

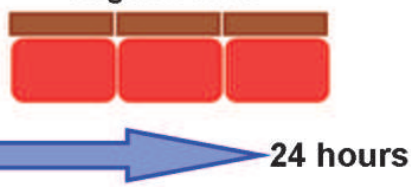

Fig. 8. In healthy patients the umbrella cell layer lining the lumen of the urinary bladder is renewed every few months (A). However, epithelial cells exfoliate within 6 hours after infection with an invasive uropathogen (B). This excretory process allows for effective excretion of infected urothelial cells. Within 24 hours of exfoliation proliferation cascades induce effective regeneration of a new umbrella cell layer.

Apart from triggering the initial inflammatory response, recruited neutrophils are also important for providing resistance to UTIs as demonstrated in one study on mice (Haraoka et al. 1999). Results from this study showed that UTIs are persistent in mice with specific genetic backgrounds and that UTIs will resolve spontaneously in mice with normal backgrounds. These findings suggest that specific host genes may be important for effective resolution of the UTI as demonstrated in another study on mice where TLR11 recognised uropathogenic E. coli and prevented its ascension into the kidneys (Hopkins et al. 1998). Interestingly, TLR11 is truncated in humans and susceptibility for pyelonephritis is increased. Furthermore, a study by Mysorekar et al demonstrated that females with recurrent UTIs had reduced levels of CD16 which led to decreased bacterial phagocytosis (Mysorekar et al. 2002).

The urinary tract is a component of the secretory immune system as it is the first defence system encountered by invading uropathogens. Infections of the kidneys are associated with serum and kidney immunoglobulin synthesis and type specific antibodies have been detected in the host's urine. Serum antibodies targeting type 1 and $\mathrm{P}$ pili have been detected after episodes of pyelonephritis with IgG and SIgA antibodies also detected in the urine (Rene et al. 1982). Synthesis of these specific antibodies occurs locally to enhance the opsonisation process in infected patients and to reduce adherence of E. coli (de Ree and van den Bosch 1987). The potential for modifying these immunological factors to decrease the 
incidence of UTIs in susceptible patients has been explored through immunisation techniques in animal models. Vaccination with $\mathrm{P}$ fimbria has been shown to decrease adherence of P-fimbriated E. coli to uroepithelial cells and prevent pyelonephritis in monkeys (Roberts and Phillips 1979). In addition, vaccination with FimH adhesin has been shown to prevent cystitis in mice (Langermann et al. 1997). It is therefore plausible that vaccination techniques may reduce colonisation and ascending infections in susceptible female patients (Uehling et al. 1994a, Uehling et al. 1994b).

\section{Conclusions}

A renewed interest in the pathogenesis of UTIs has developed over recent years. Pathogenic mechanisms are complicated and influenced by the biological and behavioural features of the host as well as adhesins from the invading uropathogen. Advances at a molecular level have led to a greater understanding in adherence mechanisms between bacterial virulence factors and the host's uroepithelial receptors. An improved understanding of these pathogenic mechanisms and associated host risk factors is important for developing novel strategies for the treatment and prevention of UTIs.

\section{References}

Abrutyn, E., Boscia, J. A. and Kaye, D. (1988) 'The treatment of asymptomatic bacteriuria in the elderly', J Am Geriatr Soc, 36(5), 473-5.

Anderson, G. G., Dodson, K. W., Hooton, T. M. and Hultgren, S. J. (2004a) 'Intracellular bacterial communities of uropathogenic Escherichia coli in urinary tract pathogenesis', Trends Microbiol, 12(9), 424-30.

Anderson, G. G., Martin, S. M. and Hultgren, S. J. (2004b) 'Host subversion by formation of intracellular bacterial communities in the urinary tract', Microbes Infect, 6(12), 1094101.

Bonadio, M., Meini, M., Gigli, C., Longo, B. and Vigna, A. (1999) 'Urinary tract infection in diabetic patients', Urol Int, 63(4), 215-9.

Bronsema, D. A., Adams, J. R., Pallares, R. and Wenzel, R. P. (1993) 'Secular trends in rates and etiology of nosocomial urinary tract infections at a university hospital', J Urol, 150(2 Pt 1), 414-6.

Brooks, H. J., Benseman, B. A., Peck, J. and Bettelheim, K. A. (1981) 'Correlation between uropathogenic properties of Escherichia coli from urinary tract infections and the antibody-coated bacteria test and comparison with faecal strains', J Hyg (Lond), 87(1), 53-61.

Busch, R. and Huland, H. (1984) 'Correlation of symptoms and results of direct bacterial localization in patients with urinary tract infections', J Urol, 132(2), 282-5.

Coker, C., Poore, C. A., Li, X. and Mobley, H. L. (2000) 'Pathogenesis of Proteus mirabilis urinary tract infection', Microbes Infect, 2(12), 1497-505.

de Ree, J. M. and van den Bosch, J. F. (1987) 'Serological response to the P fimbriae of uropathogenic Escherichia coli in pyelonephritis', Infect Immun, 55(9), $2204-7$.

Eden, C. S., Hanson, L. A., Jodal, U., Lindberg, U. and Akerlund, A. S. (1976) 'Variable adherence to normal human urinary-tract epithelial cells of Escherichia coli strains associated with various forms of urinary-tract infection', Lancet, 1(7984), 490-2. 
Eschenbach, D. A., Davick, P. R., Williams, B. L., Klebanoff, S. J., Young-Smith, K., Critchlow, C. M. and Holmes, K. K. (1989) 'Prevalence of hydrogen peroxideproducing Lactobacillus species in normal women and women with bacterial vaginosis', J Clin Microbiol, 27(2), 251-6.

Fihn, S. D., Boyko, E. J., Chen, C. L., Normand, E. H., Yarbro, P. and Scholes, D. (1998) 'Use of spermicide-coated condoms and other risk factors for urinary tract infection caused by Staphylococcus saprophyticus', Arch Intern Med, 158(3), 281-7.

Fihn, S. D., Boyko, E. J., Normand, E. H., Chen, C. L., Grafton, J. R., Hunt, M., Yarbro, P., Scholes, D. and Stergachis, A. (1996) 'Association between use of spermicide-coated condoms and Escherichia coli urinary tract infection in young women', Am J Epidemiol, 144(5), 512-20.

Forland, M., Thomas, V. and Shelokov, A. (1977) 'Urinary tract infections in patients with diabetes mellitus. Studies on antibody coating of bacteria', JAMA, 238(18), 1924-6.

Fowler, J. E., Jr. and Stamey, T. A. (1977) 'Studies of introital colonization in women with recurrent urinary infections. VII. The role of bacterial adherence', J Urol, 117(4), 472-6.

Foxman, B. (2002) 'Epidemiology of urinary tract infections: incidence, morbidity, and economic costs', Am J Med, 113 Suppl 1A, 5S-13S.

Foxman, B., Marsh, J., Gillespie, B., Rubin, N., Koopman, J. S. and Spear, S. (1997) 'Condom use and first-time urinary tract infection', Epidemiology, 8(6), 637-41.

Freedman, L. R. (1975) 'Natural history of urinary infection in adults', Kidney Int Suppl, 4, S96-100.

Frendeus, B., Godaly, G., Hang, L., Karpman, D., Lundstedt, A. C. and Svanborg, C. (2000) 'Interleukin 8 receptor deficiency confers susceptibility to acute experimental pyelonephritis and may have a human counterpart', J Exp Med, 192(6), 881-90.

Frendeus, B., Godaly, G., Hang, L., Karpman, D. and Svanborg, C. (2001) 'Interleukin-8 receptor deficiency confers susceptibility to acute pyelonephritis', J Infect Dis, 183 Suppl 1, S56-60.

Godaly, G., Frendeus, B., Proudfoot, A., Svensson, M., Klemm, P. and Svanborg, C. (1998) 'Role of fimbriae-mediated adherence for neutrophil migration across Escherichia coli-infected epithelial cell layers', Mol Microbiol, 30(4), 725-35.

Godaly, G., Proudfoot, A. E., Offord, R. E., Svanborg, C. and Agace, W. W. (1997) 'Role of epithelial interleukin-8 (IL-8) and neutrophil IL-8 receptor A in Escherichia coliinduced transuroepithelial neutrophil migration', Infect Immun, 65(8), 3451-6.

Gruneberg, R. N. (1969) 'Relationship of infecting urinary organism to the faecal flora in patients with symptomatic urinary infection', Lancet, 2(7624), 766-8.

Gupta, K., Scholes, D. and Stamm, W. E. (1999) 'Increasing prevalence of antimicrobial resistance among uropathogens causing acute uncomplicated cystitis in women', JAMA, 281(8), 736-8.

Gupta, K., Stapleton, A. E., Hooton, T. M., Roberts, P. L., Fennell, C. L. and Stamm, W. E. (1998) 'Inverse association of H2O2-producing lactobacilli and vaginal Escherichia coli colonization in women with recurrent urinary tract infections', J Infect Dis, 178(2), 446-50.

Handley, M. A., Reingold, A. L., Shiboski, S. and Padian, N. S. (2002) 'Incidence of acute urinary tract infection in young women and use of male condoms with and without nonoxynol-9 spermicides', Epidemiology, 13(4), 431-6. 
Haraoka, M., Hang, L., Frendeus, B., Godaly, G., Burdick, M., Strieter, R. and Svanborg, C. (1999) 'Neutrophil recruitment and resistance to urinary tract infection', J Infect Dis, 180(4), 1220-9.

Haspels, A. A., Luisi, M. and Kicovic, P. M. (1981) 'Endocrinological and clinical investigations in post-menopausal women following administration of vaginal cream containing oestriol', Maturitas, 3(3-4), 321-7.

Hawes, S. E., Hillier, S. L., Benedetti, J., Stevens, C. E., Koutsky, L. A., Wolner-Hanssen, P. and Holmes, K. K. (1996) 'Hydrogen peroxide-producing lactobacilli and acquisition of vaginal infections', J Infect Dis, 174(5), 1058-63.

Herthelius-Elman, M., Mollby, R., Nord, C. E. and Winberg, J. (1992) 'The effect of amoxycillin on vaginal colonization resistance and normal vaginal flora in monkeys', J Antimicrob Chemother, 29(3), 329-40.

Hillier, S. L., Krohn, M. A., Klebanoff, S. J. and Eschenbach, D. A. (1992) 'The relationship of hydrogen peroxide-producing lactobacilli to bacterial vaginosis and genital microflora in pregnant women', Obstet Gynecol, 79(3), 369-73.

Hooton, T. M. (2000) 'Pathogenesis of urinary tract infections: an update', J Antimicrob Chemother, 46 Suppl A, 1-7.

Hooton, T. M., Fennell, C. L., Clark, A. M. and Stamm, W. E. (1991a) 'Nonoxynol-9: differential antibacterial activity and enhancement of bacterial adherence to vaginal epithelial cells', J Infect Dis, 164(6), 1216-9.

Hooton, T. M., Hillier, S., Johnson, C., Roberts, P. L. and Stamm, W. E. (1991b) 'Escherichia coli bacteriuria and contraceptive method', JAMA, 265(1), 64-9.

Hooton, T. M., Scholes, D., Hughes, J. P., Winter, C., Roberts, P. L., Stapleton, A. E., Stergachis, A. and Stamm, W. E. (1996a) 'A prospective study of risk factors for symptomatic urinary tract infection in young women', N Engl J Med, 335(7), 468-74.

Hooton, T. M., Scholes, D., Stapleton, A. E., Roberts, P. L., Winter, C., Gupta, K., Samadpour, M. and Stamm, W. E. (2000) 'A prospective study of asymptomatic bacteriuria in sexually active young women', N Engl J Med, 343(14), 992-7.

Hooton, T. M. and Stamm, W. E. (1997) 'Diagnosis and treatment of uncomplicated urinary tract infection', Infect Dis Clin North Am, 11(3), 551-81.

Hooton, T. M., Winter, C., Tiu, F. and Stamm, W. E. (1996b) 'Association of acute cystitis with the stage of the menstrual cycle in young women', Clin Infect Dis, 23(3), 635-6.

Hopkins, W. J., Gendron-Fitzpatrick, A., Balish, E. and Uehling, D. T. (1998) 'Time course and host responses to Escherichia coli urinary tract infection in genetically distinct mouse strains', Infect Immun, 66(6), 2798-802.

Hultgren, S. J., Schwan, W. R., Schaeffer, A. J. and Duncan, J. L. (1986) 'Regulation of production of type 1 pili among urinary tract isolates of Escherichia coli', Infect Immun, 54(3), 613-20.

Iosif, C. S. and Bekassy, Z. (1984) 'Prevalence of genito-urinary symptoms in the late menopause', Acta Obstet Gynecol Scand, 63(3), 257-60.

Jones, C. H., Pinkner, J. S., Roth, R., Heuser, J., Nicholes, A. V., Abraham, S. N. and Hultgren, S. J. (1995) 'FimH adhesin of type 1 pili is assembled into a fibrillar tip structure in the Enterobacteriaceae', Proc Natl Acad Sci U S A, 92(6), 2081-5.

Justice, S. S., Hung, C., Theriot, J. A., Fletcher, D. A., Anderson, G. G., Footer, M. J. and Hultgren, S. J. (2004) 'Differentiation and developmental pathways of 
uropathogenic Escherichia coli in urinary tract pathogenesis', Proc Natl Acad Sci U S A, 101(5), 1333-8.

Kallenius, G., Mollby, R., Svenson, S. B. and Winberg, J. (1981) 'Microbial adhesion and the urinary tract', Lancet, 2(8251), 866.

Kau, A. L., Hunstad, D. A. and Hultgren, S. J. (2005) 'Interaction of uropathogenic Escherichia coli with host uroepithelium', Curr Opin Microbiol, 8(1), 54-9.

Kennedy, R. P., Plorde, J. J. and Petersdorf, R. G. (1965) 'Studies on the Epidemiology of Escherichia Coli Infections. Iv. Evidence for a Nosocomial Flora', J Clin Invest, 44, 193-201.

Khan, S. W. and Ahmed, A. (2001) 'Uropathogens and their susceptibility pattern: a retrospective analysis', J Pak Med Assoc, 51(2), 98-100.

Kisielius, P. V., Schwan, W. R., Amundsen, S. K., Duncan, J. L. and Schaeffer, A. J. (1989) 'In vivo expression and variation of Escherichia coli type 1 and $\mathrm{P}$ pili in the urine of adults with acute urinary tract infections', Infect Immun, 57(6), 1656-62.

Klemm, P. (1985) 'Fimbrial adhesions of Escherichia coli', Rev Infect Dis, 7(3), 321-40.

Klumpp, D. J., Weiser, A. C., Sengupta, S., Forrestal, S. G., Batler, R. A. and Schaeffer, A. J. (2001) 'Uropathogenic Escherichia coli potentiates type 1 pilus-induced apoptosis by suppressing NF-kappaB', Infect Immun, 69(11), 6689-95.

Kuehn, M. J., Ogg, D. J., Kihlberg, J., Slonim, L. N., Flemmer, K., Bergfors, T. and Hultgren, S. J. (1993) 'Structural basis of pilus subunit recognition by the PapD chaperone', Science, 262(5137), 1234-41.

Langermann, S., Palaszynski, S., Barnhart, M., Auguste, G., Pinkner, J. S., Burlein, J., Barren, P., Koenig, S., Leath, S., Jones, C. H. and Hultgren, S. J. (1997) 'Prevention of mucosal Escherichia coli infection by FimH-adhesin-based systemic vaccination', Science, 276(5312), 607-11.

Lau, Y. E., Rozek, A., Scott, M. G., Goosney, D. L., Davidson, D. J. and Hancock, R. E. (2005) 'Interaction and cellular localization of the human host defense peptide LL-37 with lung epithelial cells', Infect Immun, 73(1), 583-91.

Lipsky, B. A. (1989) 'Urinary tract infections in men. Epidemiology, pathophysiology, diagnosis, and treatment', Ann Intern Med, 110(2), 138-50.

Malaviya, R. and Abraham, S. N. (1998) 'Clinical implications of mast cell-bacteria interaction', J Mol Med, 76(9), 617-23.

McCarty, J. M., Richard, G., Huck, W., Tucker, R. M., Tosiello, R. L., Shan, M., Heyd, A. and Echols, R. M. (1999) 'A randomized trial of short-course ciprofloxacin, ofloxacin, or trimethoprim/sulfamethoxazole for the treatment of acute urinary tract infection in women. Ciprofloxacin Urinary Tract Infection Group', Am J Med, 106(3), $292-9$.

McGroarty, J. A., Soboh, F., Bruce, A. W. and Reid, G. (1990) 'The spermicidal compound nonoxynol-9 increases adhesion of Candida species to human epithelial cells in vitro', Infect Immun, 58(6), 2005-7.

Mobley, H. L., Island, M. D. and Massad, G. (1994) 'Virulence determinants of uropathogenic Escherichia coli and Proteus mirabilis', Kidney Int Suppl, 47, S129-36.

Mulvey, M. A. (2002) 'Adhesion and entry of uropathogenic Escherichia coli', Cell Microbiol, $4(5), 257-71$.

Mulvey, M. A., Lopez-Boado, Y. S., Wilson, C. L., Roth, R., Parks, W. C., Heuser, J. and Hultgren, S. J. (1998) 'Induction and evasion of host defenses by type 1-piliated uropathogenic Escherichia coli', Science, 282(5393), 1494-7. 
Mulvey, M. A., Schilling, J. D., Martinez, J. J. and Hultgren, S. J. (2000) 'Bad bugs and beleaguered bladders: interplay between uropathogenic Escherichia coli and innate host defenses', Proc Natl Acad Sci U S A, 97(16), 8829-35.

Munoz, P., Llancaqueo, A., Rodriguez-Creixems, M., Pelaez, T., Martin, L. and Bouza, E. (1997) 'Group B streptococcus bacteremia in nonpregnant adults', Arch Intern Med, 157(2), 213-6.

Mysorekar, I. U., Mulvey, M. A., Hultgren, S. J. and Gordon, J. I. (2002) 'Molecular regulation of urothelial renewal and host defenses during infection with uropathogenic Escherichia coli', J Biol Chem, 277(9), 7412-9.

Nicolle, L. E., Friesen, D., Harding, G. K. and Roos, L. L. (1996) 'Hospitalization for acute pyelonephritis in Manitoba, Canada, during the period from 1989 to 1992; impact of diabetes, pregnancy, and aboriginal origin', Clin Infect Dis, 22(6), 1051-6.

Parsek, M. R. and Singh, P. K. (2003) 'Bacterial biofilms: an emerging link to disease pathogenesis', Annu Rev Microbiol, 57, 677-701.

Poljakovic, M. and Persson, K. (2003) 'Urinary tract infection in iNOS-deficient mice with focus on bacterial sensitivity to nitric oxide', Am J Physiol Renal Physiol, 284(1), F2231.

Poljakovic, M., Svensson, M. L., Svanborg, C., Johansson, K., Larsson, B. and Persson, K. (2001) 'Escherichia coli-induced inducible nitric oxide synthase and cyclooxygenase expression in the mouse bladder and kidney', Kidney Int, 59(3), 893-904.

Raz, R. (2001) 'Postmenopausal women with recurrent UTI', Int J Antimicrob Agents, 17(4), 269-71.

Raz, R., Gennesin, Y., Wasser, J., Stoler, Z., Rosenfeld, S., Rottensterich, E. and Stamm, W. E. (2000) 'Recurrent urinary tract infections in postmenopausal women', Clin Infect Dis, 30(1), 152-6.

Raz, R. and Stamm, W. E. (1993) 'A controlled trial of intravaginal estriol in postmenopausal women with recurrent urinary tract infections', N Engl J Med, 329(11), 753-6.

Reid, G. and Sobel, J. D. (1987) 'Bacterial adherence in the pathogenesis of urinary tract infection: a review', Rev Infect Dis, 9(3), 470-87.

Rene, P., Dinolfo, M. and Silverblatt, F. J. (1982) 'Serum and urogenital antibody responses to Escherichia coli pili in cystitis', Infect Immun, 38(2), 542-7.

Roberts, A. P. and Phillips, R. (1979) 'Bacteria causing symptomatic urinary tract infection or asymptomatic bacteriuria', J Clin Pathol, 32(5), 492-6.

Ronald, A. (2003) 'The etiology of urinary tract infection: traditional and emerging pathogens', Dis Mon, 49(2), 71-82.

Ronald, A. and Ludwig, E. (2001) 'Urinary tract infections in adults with diabetes', Int J Antimicrob Agents, 17(4), 287-92.

Rosenstein, I. J., Stafford, M. K., Kitchen, V. S., Ward, H., Weber, J. N. and Taylor-Robinson, D. (1998) 'Effect on normal vaginal flora of three intravaginal microbicidal agents potentially active against human immunodeficiency virus type 1', J Infect Dis, 177(5), 1386-90.

Schaeffer, A. J., Jones, J. M. and Dunn, J. K. (1981) 'Association of vitro Escherichia coli adherence to vaginal and buccal epithelial cells with susceptibility of women to recurrent urinary-tract infections', N Engl J Med, 304(18), 1062-6.

Schaeffer, A. J., Radvany, R. M. and Chmiel, J. S. (1983) 'Human leukocyte antigens in women with recurrent urinary tract infections', J Infect Dis, 148(3), 604. 
Schaeffer, A. J., Schwan, W. R., Hultgren, S. J. and Duncan, J. L. (1987) 'Relationship of type 1 pilus expression in Escherichia coli to ascending urinary tract infections in mice', Infect Immun, 55(2), 373-80.

Schlager, T. A. (2001) 'Urinary tract infections in children younger than 5 years of age: epidemiology, diagnosis, treatment, outcomes and prevention', Paediatr Drugs, 3(3), 219-27.

Schlager, T. A., Hendley, J. O., Bell, A. L. and Whittam, T. S. (2002) 'Clonal diversity of Escherichia coli colonizing stools and urinary tracts of young girls', Infect Immun, 70(3), 1225-9.

Smellie, J., Edwards, D., Hunter, N., Normand, I. C. and Prescod, N. (1975) 'Vesico-ureteric reflux and renal scarring', Kidney Int Suppl, 4, S65-72.

Smith, H. S., Hughes, J. P., Hooton, T. M., Roberts, P., Scholes, D., Stergachis, A., Stapleton, A. and Stamm, W. E. (1997) 'Antecedent antimicrobial use increases the risk of uncomplicated cystitis in young women', Clin Infect Dis, 25(1), 63-8.

Stamm, W. E. and Hooton, T. M. (1993) 'Management of urinary tract infections in adults', N Engl J Med, 329(18), 1328-34.

Stapleton, A. (2002) 'Urinary tract infections in patients with diabetes', Am J Med, 113 Suppl $1 \mathrm{~A}, 80 \mathrm{~S}-84 \mathrm{~S}$.

Sun, T. T. (1996) 'Epithelial growth and differentiation: an overview', Mol Biol Rep, 23(1), 1-2.

Talan, D. A., Stamm, W. E., Hooton, T. M., Moran, G. J., Burke, T., Iravani, A., ReuningScherer, J. and Church, D. A. (2000) 'Comparison of ciprofloxacin (7 days) and trimethoprim-sulfamethoxazole (14 days) for acute uncomplicated pyelonephritis pyelonephritis in women: a randomized trial', JAMA, 283(12), 1583-90.

Thomas, T. M., Plymat, K. R., Blannin, J. and Meade, T. W. (1980) 'Prevalence of urinary incontinence', Br Med J, 281(6250), 1243-5.

Uehling, D. T., Hopkins, W. J., Dahmer, L. A. and Balish, E. (1994a) 'Phase I clinical trial of vaginal mucosal immunization for recurrent urinary tract infection', J Urol, 152(6 Pt 2), 2308-11.

Uehling, D. T., Hopkins, W. J., James, L. J. and Balish, E. (1994b) 'Vaginal immunization of monkeys against urinary tract infection with a multi-strain vaccine', J Urol, 151(1), 214-6.

Vaisanen, V., Elo, J., Tallgren, L. G., Siitonen, A., Makela, P. H., Svanborg-Eden, C., Kallenius, G., Svenson, S. B., Hultberg, H. and Korhonen, T. (1981) 'Mannoseresistant haemagglutination and $\mathrm{P}$ antigen recognition are characteristic of Escherichia coli causing primary pyelonephritis', Lancet, 2(8260-61), 1366-9.

Vetsch, M., Puorger, C., Spirig, T., Grauschopf, U., Weber-Ban, E. U. and Glockshuber, R. (2004) 'Pilus chaperones represent a new type of protein-folding catalyst', Nature, 431(7006), 329-33.

Vosti, K. L., Goldberg, L. M., Monto, A. S. and Rantz, L. A. (1964) 'Host-Parasite Interaction in Patients with Infections Due to Escherichia Coli. I. The Serogrouping of E. Coli from Intestinal and Extraintestinal Sources', J Clin Invest, 43, 2377-85.

Winberg, J., Gezelius, L., Guldevall, L. and Mollby, R. (1993) 'Cephadroxil promotes vaginal colonization with Escherichia coli', Infection, 21(4), 201-5.

Wright, S. W., Wrenn, K. D. and Haynes, M. L. (1999) 'Trimethoprim-sulfamethoxazole resistance among urinary coliform isolates', J Gen Intern Med, 14(10), 606-9. 
Wu, X. R., Sun, T. T. and Medina, J. J. (1996) 'In vitro binding of type 1-fimbriated Escherichia coli to uroplakins Ia and Ib: relation to urinary tract infections', Proc Natl Acad Sci U S A, 93(18), 9630-5.

Yamamoto, S., Tsukamoto, T., Terai, A., Kurazono, H., Takeda, Y. and Yoshida, O. (1997) 'Genetic evidence supporting the fecal-perineal-urethral hypothesis in cystitis caused by Escherichia coli', J Urol, 157(3), 1127-9.

Zhang, D., Zhang, G., Hayden, M. S., Greenblatt, M. B., Bussey, C., Flavell, R. A. and Ghosh, S. (2004) 'A toll-like receptor that prevents infection by uropathogenic bacteria', Science, 303(5663), 1522-6. 


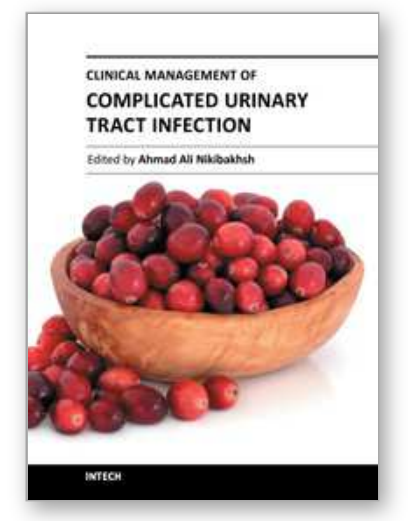

\author{
Clinical Management of Complicated Urinary Tract Infection \\ Edited by Dr. Ahmad Nikibakhsh
}

ISBN 978-953-307-393-4

Hard cover, 294 pages

Publisher InTech

Published online 06, September, 2011

Published in print edition September, 2011

Complicated urinary tract infections (cUTIs) are a major cause of hospital admissions and are associated with significant morbidity and health care costs. Knowledge of baseline risk of urinary tract infection can help clinicians make informed diagnostic and therapeutic decisions. Prevalence rates of UTI vary by age, gender, race, and other predisposing risk factors. In this regard, this book provides comprehensive information on etiology, epidemiology, immunology, pathology, pathogenic mechanisms, symptomatology, investigation and management of urinary tract infection. Chapters cover common problems in urinary tract infection and put emphasis on the importance of making a correct clinical decision and choosing the appropriate therapeutic approach. Topics are organized to address all of the major complicated conditions frequently seen in urinary tract infection. The authors have paid particular attention to urological problems like the outcome of patients with vesicoureteric reflux, the factors affecting renal scarring, obstructive uropathy, voiding dysfunction and catheter associated problems. This book will be indispensable for all professionals involved in the medical care of patients with urinary tract infection.

\title{
How to reference
}

In order to correctly reference this scholarly work, feel free to copy and paste the following:

Niall F. Davis and Hugh D. Flood (2011). The Pathogenesis of Urinary Tract Infections, Clinical Management of Complicated Urinary Tract Infection, Dr. Ahmad Nikibakhsh (Ed.), ISBN: 978-953-307-393-4, InTech, Available from: http://www.intechopen.com/books/clinical-management-of-complicated-urinary-tractinfection/the-pathogenesis-of-urinary-tract-infections

\section{INTECH}

open science | open minds

\section{InTech Europe}

University Campus STeP Ri

Slavka Krautzeka 83/A

51000 Rijeka, Croatia

Phone: +385 (51) 770447

Fax: +385 (51) 686166

www.intechopen.com

\section{InTech China}

Unit 405, Office Block, Hotel Equatorial Shanghai

No.65, Yan An Road (West), Shanghai, 200040, China 中国上海市延安西路65号上海国际贵都大饭店办公楼405单元

Phone: +86-21-62489820

Fax: +86-21-62489821 
(C) 2011 The Author(s). Licensee IntechOpen. This chapter is distributed under the terms of the Creative Commons Attribution-NonCommercialShareAlike-3.0 License, which permits use, distribution and reproduction for non-commercial purposes, provided the original is properly cited and derivative works building on this content are distributed under the same license. 